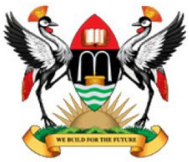

East African School of

Higher Education Studies \& Development

\title{
Effectiveness of Study Centres in Supporting Open and Distance Learning at Makerere University
}

\author{
Nabushawo Harriet Mutambo ${ }^{1,}{ }^{*}$, Jessica Norah Aguti ${ }^{1}$, Mark Winterbottom ${ }^{2}$ \\ ${ }^{1}$ Makerere University [ ${ }^{*}$ Corresponding author: hnabushawo@gmail.com], ${ }^{2}$ University of \\ Cambridge
}

\begin{abstract}
In open and distance learning (ODL), the teacher and student are separated in time and space for most of the time. To ensure continuity of teaching and learning, learner support mechanisms are required. Rumble (1992) contends that for effective support these mechanisms should be decentralized and accessible to students. It is with this understanding that this study examined the effectiveness of Makerere University's study centres in supporting teaching and learning in its ODL programmes. Following a survey design, data was elicited from 422 respondents who included students and staff of the University. This was done using questionnaires, interviews, focus group discussions and documentary analysis. The findings were that the centres are relevant to offering remote learner support, especially given the low level of technological advancement in Uganda. However, due to a number of factors, the centres are not offering satisfactory support to the students. These include the centres' indistinct status and mandate; gaps in the University's policies and understanding of ODL; inadequate funding of the centres; communication gaps between the centres and their coordinating unit at the University's main campus; inadequacy of study, ICT and human resources at the centres; and unconducive location and opening hours of the centres. Recommendations for the better performance of the centres are discussed.
\end{abstract}

Keywords: ODL; Study centres; Student support services.

\section{$1 \quad$ Introduction}

The increasing demand for higher education has forced institutions to be more innovative in their course offerings, so as to accommodate all qualifying students including those who are interested in professional development and adult education. Open and Distance Learning (ODL) has been adopted as a means of meeting this demand (UNESCO, 2002).

According to Perraton (1993), ODL is a process where teachers and learners are separated in space and/ or time for a significant portion of their education. 
However, to ensure continuity of teaching and learning, learner support mechanisms are usually put in place. Direct student-support is one key component that enables students to cope with the challenges of isolation, and hence to progress and stay motivated.

Student-support services in ODL are rooted in social constructivist theories advanced by Vygotsky (1978) which emphasises collaborative learning. This is where knowledge is socially constructed through peer tutoring. This involves students working in pairs or small groups to discuss concepts or find solutions to academic problems. Such educational experiences that are active, social, contextual, engaging, and student-owned lead to deeper learning and development of higher-level thinking (Simpson, 2013). Indeed, Moore (1993)'s theory of transactional distance posits that the space between the learner and the structure of teaching must be mediated by dialogue (Tait, 2003). With growing innovation in ICTs, dialogue between the tutor and the learners and among the learners can be enhanced using different platforms like chat rooms, discussion forums, podcasts, video clips, blogs, and wikis (Pact, 2014).

There are a range of student services given to individuals and groups of students to support teaching and learning (Tait, 2000). These services are both academic and administrative and involve face to face or virtually interaction. With advancement in technology, student support is being provided on different platforms like emails, discussion forums, social media and on-line chats (Simpson, 2013).

Support services are very important in any ODL programme. They should be designed at the initial planning phase of the ODL programme and should be "fit for purpose" (Mills, 2003). Indeed, the way these services are provided differs across institutions, depending on the context and teaching philosophy of the institutions (Bbuye, 2012).

The Open University (OU) in the UK champions high quality ODL by putting in place strong institutions and structures to support students. The management of student support services at OU was based on a decentralized model, which was relatively effective (Rumble, 1992). This was because the study centres increased students' access to educational services, such as tutorial assistance, library resources, and interaction with tutors and fellow students. This structure has been replicated across the world. However, in some countries, support services in ODL institutions have not been well managed and this consequently affects the teaching and learning process (Aguti, 2004; Bbuye, 2012).

\subsection{Role of Study Centres in ODL}

Study centres are an extension arm of a university to the community. They operate in different forms. In some ODL institutions, they operate as residential schools; in others they serve only as centres for tutorials or for material 
distribution (Ipaye, 2008). The tutors in these centres support students and motivate them to keep on the programme, providing timely feedback to their queries, both academic and administrative.

To ensure that these activities and facilities are running, there is need for institutional commitment. Ipaye (2008) contends that to sustain a study centre, funding must be regular and adequate, contact between the study centre and main campus must be cordial, and staff at the study centre should be friendly and familiar with learners' problems.

However, in many ODL institutions, these centres do not have a clear position within the institutional structure. This lack of clarity can result in a reduced budget and a transition only to provision of ad hoc support, which itself can foster increased rates of course withdrawal. Nanyongo (2002) for example cites low success in terms of completion and throughput rates in UNISA due to inadequate learner support, which was exacerbated by a lack of coordinated regional learning centres. Mills (2003) similarly reports a high drop-out rate of 50\% in a large and relatively successful institution of OU; he attributes this to new policies that saw a systematic and steady reduction of resourcing for regional support services. Due to this status, Simpson (2013) reports that the graduation and retention rates at $\mathrm{OU}$ have fallen by up to $22 \%$.

In institutions still running second generation ODL, the study centres are still relevant to offer personalized and localized support, particularly in contexts where ICT infrastructure is poor. Contemporary Web 2.0 technology, such as podcasts, forums, video clips and wikis may provide better opportunity for learning as materials and tutors can be accessed online. Similarly, mobile phone technology is popular, but the quality of phones students possess are limited in terms of internet capacity, storage and transmission (Pact, 2014). The level of technological integration in teaching and learning processes is still too low to offer effective and efficient remote support. Therefore, the most appropriate support may be provided through study centres.

\subsection{ODL Support Services and Study Centres at Makerere University}

To meet the increasing demand for higher education in Uganda, Makerere University introduced a flexible mode of study that could take in large numbers of students, especially those who are disadvantaged due to social, economic and geographical factors. Such "distance education" is flexible in that it allows one to study while working and taking care of other obligations. The university introduced the Bachelor of Education (B. Ed.) External Degree Programme in 1991. Like any other distance education programme, student support is key to ensuring the continuity of learning while away from the main campus (Bbuye, 2012). At Makerere University, student support services comprise occasional oncampus face-to-face sessions, study group meetings, upcountry study centres, 
access to library services and opportunities for students to interact with tutors (Aguti, 2004). The study centres aim to provide ODL students with tutorial, library, reading and discussion space plus administration (including assignment submission and registration). However, according to Wrightson and Otto (2005) the centres are poorly resourced. Therefore, this study was conducted to provide an evaluation of the effectiveness of the centres in supporting the University's ODL programmes. The study attempted to respond to the following specific research questions:

1. How have Makerere University upcountry study centres supported ODL students?

2. What are the barriers to effectiveness of ODL study centres?

\section{$2 \quad$ Methods}

The study employed qualitative and quantitative approaches to data gathering and analysis. Data were collected from four of the nine upcountry study centres. These were purposely selected from the four regions of Uganda (i.e. Central, East, North and West). Cluster sampling was used to select 300 students out of the 3500 students on the University's B.Ed. programme. The clusters of B.Ed. students included 90 year one students and 210 year three students. The students were asked to share their experiences regarding the support they had received since joining the programme. Other key informants were also purposively selected to participate in the study: four study centre coordinators, four librarians, five lecturers on the B. Ed. programme, three ICT administrators, and six members of staff from the Department of Distance Education. Information from students was gathered using a structured questionnaire, interviews and focus group discussions (FGDs). FGDs were held in each of the study centres and these included 7-10 students and key informants. An observation checklist was used to study the facilities available to students at each of the centres. Relevant documentary evidence was examined to triangulate the information obtained from the questionnaires and FGDs. The data was analysed using descriptive statistics and content analysis.

\section{$3 \quad$ Findings and Discussion}

\subsection{Support towards ODL Students at Study Centres}

The study began by asking the students to rate the support services on the B.Ed. programme. In response, most of them maintained that the support systems were poor (Table 1). 
Table 1: Students' Ratings of the Services and Facilities available in the Study Centres

\begin{tabular}{|c|c|c|c|c|c|}
\hline $\begin{array}{l}\text { To what extent would you } \\
\text { agree that the following are } \\
\text { available in your study centre? }\end{array}$ & $\begin{array}{l}\text { Strongly } \\
\text { agree }\end{array}$ & Agree & Disagree & $\begin{array}{l}\text { Strongly } \\
\text { disagree }\end{array}$ & Total \\
\hline ICTs & $20(6.7 \%)$ & $13(4.3 \%)$ & 139 (46.3\%) & $128(42.7 \%)$ & 300 (100\%) \\
\hline Reading space and discussions & $37(12.3 \%)$ & $95(31.7 \%)$ & $67(22.3 \%)$ & $101(33.7 \%)$ & $300(100 \%)$ \\
\hline Library services & $115(38.3 \%)$ & $138(46.0 \%)$ & $36(12.0 \%)$ & $11(3.7 \%)$ & $300(100 \%)$ \\
\hline Staffing & $20(6.7 \%)$ & $37(12.3 \%)$ & $128(42.7 \%)$ & 115 (38.3\%) & 300 (100\%) \\
\hline
\end{tabular}

The students cited the following reasons for rating the quality of support at the centres as poor: poor student-tutor interaction, ill-prepared tutors, and absence of student study groups. One B.Ed. student said;

"There is no support you get from the department while at home, if you have an academic related query, you have to travel back to main campus because there are no tutors at the nearest centres".

Student support services ought to be provided to distance learners both at the main campus and at the study centres. However, all of these services are being offered centrally with only a few being provided at the study centres. Hence, although there is a framework for learner support in place, it has not been operationalized to offer continuity of learning while away from the main campus.

The responses from Table 1 indicate that students are getting minimal services from the study centres. About $88 \%$ of the students reported centres not having ICTs, $67 \%$ said there is no space for reading and discussions, while $81 \%$ claimed there was no staff to attend to them. That said, students rated library and computer resources at study centres considerably more useful than the other facilities there. As already noted, study centres are meant to offer remote support to ODL students. However, if these services are not available to them, then the quality of the education they are receiving is likely to be affected.

The students were further asked to give reasons why many of them do not utilize the study centres. The findings are summarised in Table 2.

Table 2: Factors Hindering Students from Utilizing Study Centres

\begin{tabular}{llll}
\hline $\begin{array}{l}\text { To what extent do the following factors } \\
\text { hinder your utilisation of your study centre? }\end{array}$ & To a large Extent & To a small Extent & Not at all \\
\hline Ignorance about the services at the centre & $230=77 \%$ & $69=23 \%$ & $1=0.3 \%$ \\
Inadequacy of study materials at the centre & $256=85 \%$ & $40=13 \%$ & $4=1.3 \%$ \\
Unavailability of tutors at the centre & $242=81 \%$ & $48=16 \%$ & - \\
The office is always closed & $160=53 \%$ & $130=43 \%$ & $10=3.3 \%$ \\
Lack of required information & $127=42 \%$ & $160=53 \%$ & $13=4.3 \%$ \\
Staff at the centre cannot make decisions & $260=87 \%$ & $40=13 \%$ & - \\
The centres are very far away & $145=48 \%$ & $130=43 \%$ & $25=8.3 \%$ \\
Lack of internet & $240=80 \%$ & $50=17 \%$ & $10=3.3 \%$ \\
\hline
\end{tabular}


Although study centres do exist, they do not provide adequate support to the students. That is why those interviewed contended that they do not utilize the centres. Interviews with programme administrators and centre coordinators, plus the observations made confirmed the students' claims. They contended that due to multiple factors, operations at the centres have been hampered. They cited inadequate funding, unclear policies and poor staffing. One coordinator said that:

"Previously the university administration recognized our contribution and would allocate some funds to support us but now, we do not get any support from the main campus. We reported the disconnection of internet and telephone lines but nothing has been done." Coordinator, Mbale Centre.

\subsection{Barriers to the Effectiveness of the ODL study centres}

Results from the interviews, FGDs and observation established the following factors affecting the effectiveness of the study centres in supporting distance learners.

\subsubsection{Indistinct Status and Mandate}

The status and mandate were found to be barriers to the effectiveness of the centres. The study centres were opened by the university with a clear mandate to offer outreach services (CCE, 1990). This means that study centres have a position in the university structure with authority to carry out outreach services, even though it was evident here that their services and contributions are not recognized by the central university. The poor resources are unlikely to facilitate quality services to students. For example, centres like Mbale and Lira in particular lack resourcing for student support. Students claim study materials are inadequate $(85 \%)$, that there are no tutoring services to attend to academic related challenges (81\%) and that there are no ICT facilities (80\%) (See table 2).

With time, the university has grown and decided to use some of the centres as branch campuses, hence elevating the status from that of a centre to a university wide campus. Centres like Jinja and Fort Portal have started to run regular undergraduate programmes in addition to serving as extra mural centres for short courses and supporting distance learners. This new status comes with improved facilities and resources in terms of offices, lecture rooms, library, ICT laboratories and personnel.

"---set up on February 2010 with a skeleton staff of three teaching staff and one support staff. Today we have 295 students, 15 full time and three part time teaching staff supported by eight support staff. We derive our legal status from Makerere University College Statute and External Campuses Policy". Jinja Campus website. 
The old centres (Mbale and Lira) do not have substantive coordinators but have interim organisers who have taken over these roles from their original roles as a typist and security guards. Hence, where a study centre is given a sense of purpose through a clear mandate it is more likely to be effective. This was seen in Jinja and Fort Portal where the university has improved on the teaching and learning facilities like ICTs, library services and personnel. Such improved services are likely to improve the quality of education that students receive.

\subsubsection{Policy Gaps and Limited Understanding of ODL}

To run ODL in the university, there must be guiding principles related to teaching and learning activities in the ODL mode. Absence of these principles leads to confusion and inefficiency in service delivery to the students. Results from interviews and FGDs with administrators, centre coordinators and librarians suggested that University administrators may simply be ignorant of the philosophy of teaching and learning in ODL. One programme administrator said; "When central university transfers funds to faculties, the outstanding bills they consider are those for teaching and supervision of research not for students support and development of study materials for ODL students. He said in the last four years, there has been neither a workshop for developing study materials nor any support to students upcountry".

Muyinda (2013) demonstrates this limited knowledge of university administration about ODL operations in the following scenario. In a letter responding to an application by the coordinator for Bachelor of Science (External) for a scholarship in MSc. Zoology, the Human Resources Development Committee (HRD) of Makerere University stated:

"The HRD committee wonders how Zoology will be applied in the department of Open and Distance Learning so it unanimously decided that the scholarship should not be granted. So we advise you to try other sources of funding”.

This is a committee made up of top managers of the university who are well aware that the department is running a BSc. External whose coordinator must be knowledgeable both in the content as well as the philosophy of ODL. Failure to appreciate who should work in ODL department demonstrates limited understanding of how ODL ought to be provided. This ignorance affects decision making (Mintzberg, 2004). According to Robinson (1997), the cost structure and funding needs of ODL are often not well understood by senior decision makers. The head of department of ODL said:

"Our biggest problem is the failure of the university administrators to appreciate the operations of this mode of study and the unique characteristics 
of its students. When making policies, they do not differentiate between Internal and External programmes"

Limited understanding and minimal appreciation of ODL in dual mode universities is a big factor impacting upon provision of support services, which are often inappropriate and yields stifling of ODL activities. There is therefore need for a deliberate effort to educate / sensitize university administrators about ODL operations, so as to improve the support systems to students as well as the quality of education being provided. A policy to guide the operations of ODL within and outside the university will help in enhancing support services which are central in this mode of study.

\subsubsection{Inadequate Funding and Facilitation of the Centres}

Funding is a big barrier to the effectiveness of study centres. From the students' responses, interviews and observations carried out, the study centres are illequipped to support ODL students. During the study, the coordinators for the traditional centres (Mbale and Lira) reported that they have not engaged in much activity to support ODL students because they do not have the capacity to effectively support teaching and learning activities.

"Since funding for tutorials stopped coming from the main campus, we have no other source of income to facilitate the tutorials" Coordinator, Mbale Study Centre.

The study established from the students that there is no qualified staff to competently address academic queries (81\%), the ICT infrastructure is poor $(80 \%)$, there are poor library services in the traditional centres (Mbale and Lira) and some centres do not have even space for reading and discussions (56\%).

Kember and Dekkers (1988) described an ideal study centre as one with institutional co-operation, that is physically identifiable and has proper staffing, joint funding and community involvement as essential ingredients. From observations and interviews with coordinators and programme administrators, the study found many of these facilities in a dilapidated state. For example, Mbale centre had only two computers while Lira had three but which were not connected to the internet.

According to Muyinda, (2013), increased funding leads to proactive student support services, which in turn lead to increased student retention levels. Yet there is lack of up-front preparatory development investment in ODL and although "critical mass" enrolment numbers do exist for a number of programmes, the lack of investment in infrastructure especially upcountry has compromised the quality of delivery. There may be need for the university administrators to allocate funds towards revamping of these centres if they are 
going to be used for supporting distance learners. It may also be appropriate to strengthen and broaden the finance and resources base of ODL by accessing donor funding for capacity building and infrastructural development.

\subsubsection{Communication between the Centres and Department of ODL}

Communication is key in any working relationship and it is the only way information can be effectively spread to all stakeholders in an organization for realization of organizational goals. In ODL, a communication breakdown leads to a transactional distance which provides opportunity for misunderstandings by all stakeholders. This study established that poor communication was a barrier to the effectiveness of study centres in ODL because some of the stakeholders did not have the information about the services in the centres. While some of the students knew about the existence of the centres (77\%), some were not aware of any services available there (23\%). The same students claimed not to have been referred to the centre by the programme administrators. The study established that students were holding tutorials and discussion groups in other venues because they were not aware of available working space at the centres. They spent money hiring venues out of ignorance due to poor communication. Students interviewed in Jinja, Mbale and Fort Portal were all having discussions groups outside the study centres due to limited awareness of the available facilities therein.

"We have been meeting in a school where one of us teaches because we did not know we are allowed to use the facilities at the campus" Students from Fort Portal.

The coordinators also claimed that there had been no follow up by the department of ODL regarding the centres' activities. This breakdown in communication between partner institutions affects service delivery to students. Muyinda (2013) reports that after reduction in funding for ODL activities in 2007, there have been no activities happening at the centres. This was confirmed by the Coordinator Mbale Centre who said that,

"Students come to the centre in search of particular services like typing and internet. However, since computers broke down and internet was disconnected nothing has been done even if this was reported."

According to observations and interviews with the centre coordinator, Mbale centre has only two working computers, which are not connected to the internet. A centre with such a status of facilities cannot attract students, nor offer effective academic support to the students. According to Delvane (2005), students' support services in ODL should always combine central and regional services in an integrated manner. Due to inadequate information at the centres one student said 
that, "The person in charge of the centre has to first telephone the main campus to get information at the cost of the student."

\subsubsection{Inadequate Study Materials and Library Services}

The students interviewed decried the quality and quantity of study materials at the study centres (Table 3 ).

Table 3: Resources Accessible at the Study Centres

\begin{tabular}{|c|c|c|c|c|c|}
\hline \multirow{2}{*}{\multicolumn{2}{|c|}{$\begin{array}{l}\text { Are the following materials accessible } \\
\text { at your study centre? }\end{array}$}} & \multicolumn{2}{|c|}{ Year 1} & \multicolumn{2}{|c|}{ Year 3} \\
\hline & & Count & $\%$ & Count & $\%$ \\
\hline \multirow{2}{*}{ Print material } & Yes & 85 & 94.40 & 160 & 76.20 \\
\hline & No & 5 & 5.60 & 50 & 23.80 \\
\hline \multirow{2}{*}{ Audio materials } & Yes & 5 & 5.60 & 53 & 25.20 \\
\hline & No & 85 & 94.40 & 157 & 74.80 \\
\hline \multirow{2}{*}{ Video material } & Yes & 5 & 5.60 & 5 & 2.40 \\
\hline & No & 85 & 94.40 & 205 & 97.60 \\
\hline \multirow{2}{*}{ Audio visual material } & Yes & 5 & 5.60 & 24 & 11.40 \\
\hline & No & 85 & 94.40 & 186 & 88.60 \\
\hline
\end{tabular}

The students who visited the study centres claimed not to have found the materials helpful and relevant for in-depth research for their assignments. They instead opt to go to the public library which in addition to the study materials deposited there, had a variety of other references.

"When I visited the centre, the study materials I found there were out dated and could not assist me to carry out effective research to do my course works or prepare for examinations." ODL student.

The coordinators and administrators also confirmed the poor status of the materials in the centres. Very few books had been placed at the study centres and they were seldom used.

"Some students came to borrow the study materials but did not find them useful. They said they were outdated and never came back again".

The programme administrators further reported that the provision of study materials has been stifled by inadequate funding to develop the materials as well as to buy or adapt from other institutions. One of the administrators said;

"Since the funding for ODL activities deteriorated, the department has not held any workshops for study materials development neither have any text books been purchased as supplementary references"

Study materials in ODL are very central because they are the main teaching tool and act almost as a surrogate teacher. They are meant to be specially prepared by the tutors for teaching and learning purposes. Their inadequacy or absence will affect the effectiveness of these centres since it is one of the main services 
students seek at the centre (85\%). Makerere University should therefore allocate funds towards acquisition of current and up to date study materials to facilitate continuity of teaching and learning processes.

\subsubsection{Poor ICT Infrastructure}

In this digital age, the teacher is no longer the only dispenser of knowledge and as such, computers and internet have highly complimented other modes of study. Tschanga and Santa (2000) as quoted by Aguti (2004) believe that the in ODL, use of ICTs help improve learning by getting the "--- right types of content and learning to the individuals---".This is because ICTs with internet connection facilitate in-depth study which enhances learning and promotes knowledge generation. A lot of learning materials can be accessed by students on line to enrich their studies. However, this is not the case with ODL at Makerere University as seen from the findings. From the responses of students in table 4 below, we note that the level of technological use is still low.

Table 4: Status of ICT access by students

\begin{tabular}{lllll}
\hline \multirow{2}{*}{ Type of ICT } & \multicolumn{2}{c}{ Can access } & \multicolumn{2}{c}{ Cannot access } \\
& Count & $\%$ & Count & $\%$ \\
\hline Radio & 300 & $100 \%$ & 0 & - \\
Print & 300 & $100 \%$ & 0 & - \\
Mobile phone & 280 & $93 \%$ & 20 & $2.30 \%$ \\
Television & 150 & $50 \%$ & 150 & $50 \%$ \\
Computer facilities with internet & 100 & $33 \%$ & 200 & $67 \%$ \\
\hline
\end{tabular}

The media which are popular and accessible to all students are the radio (100\%), print materials (100\%), mobile phone (93\%) and computer and internet $(33 \%)$. The radio has been widely used in ODL because of its ability to reach inaccessible areas (Aguti, 2004). Nevertheless, it is limited by signal in some areas as well as having fixed hours of transmission; this may not be convenient to the students. The mobile phone (93\%) has Increasing potential, although it also has limitations in terms of the quality of phones students possess which may be affected by internet capacity, storage and transmission (Pact, 2014). Access to a computer and the Internet is limited to $33 \%$ of students (see table 4). At the time of the study, all the centres had their internet services disconnected, apart from Fort Portal upcountry campus. The traditional extra mural centres like Mbale and Lira did not have computer facilities and internet for students' utilization. This limitation means students cannot enrich their studies using on line resources and this may limit their scope of knowledge as well. The television facilities are also popular among open and online studies however, they are still a challenge in the Ugandan context due to poor infrastructure development in Makerere, as well as in the communities where the students are scattered. Efforts 
should therefore be made by the university to have these centres networked and equipped basic ICT infrastructure with internet to support teaching and learning processes considering that the internet enable students to access a variety of on line study materials like their counterparts on the main campus.

\subsubsection{Inadequate Staffing}

From the records of the programme administrators and centre coordinators, it was found that the study centres have a skeleton staff comprising of the coordinator, secretary/clerk and security officer. This was in the traditional extra mural centres (Mbale and Lira) while for Fort Portal and Jinja their provision has been increased (see Table 5).

Table 5: Staffing of Study Centres

\begin{tabular}{lll}
\hline Title & Mbale and Lira & Jinja and Fort Portal \\
\hline Resident Tutor & NO & NO \\
Tutors / lecturers & NO & YES (14) \\
Centre Organizers / Coordinators & YES (1) & \\
Librarian & NO & YES (1) \\
ICT administrators & NO & YES (1) \\
Secretary / Records Clerk & YES (1) & YES (2) \\
Security guard & YES (1) & YES (1) \\
\hline
\end{tabular}

Source: Makerere University Website

A study centre without a resident tutor to attend to students' academic needs is not helpful, as such a scenario is a barrier to effective academic student support. Lack of qualified personnel like tutors to support students while away from the main campus slows down the students' learning processes, since feedback to students' difficulties and queries is not timely. From table 5 we also establish that centres with an elevated status of a campus, have a larger staff to provide academic support. The university administrators should develop clear working policy between ODL and the new campuses so that the students can benefit from these services and resources.

\subsubsection{Location of Study Centres}

Location was also found to be a barrier to centre effectiveness. The study centres existed in urban areas and yet many students are situated in remote rural areas and find it expensive to visit the study centre. This long distance between students and the centres has the potential to make them ineffective. While visiting the Lira centre, we found there were no students within that district. The nearest group of students was coming from Apac over $45 \mathrm{~km}$ away. Students $(48 \%)$ reported not visiting the centre because of distance from their homes. According to Kember and Dekkers (1988), the academic support offered to 
students must be related to the distribution of the students; a highly decentralized population over a wide area can make support difficult or costly. Hence, it is important for Makerere University to review the location of study centres, considering opening new centres close to student populations, in addition to the regional centres

\subsubsection{Unconducive Working Hours}

Lack of flexibility in working hours may reduce a study centre's effectiveness. Some of the students interviewed who had visited the study centres complained about the unfavourable working hours at the centre. From the study findings, $53 \%$ of the students claimed that the offices are always closed while $43 \%$ also said to a smaller extent they have been hindered from using the study centres because the offices are often closed. The closure of offices much of the time or earlier than the official time is a sign of an office that is either not busy or not well supervised (Bbuye, 2012). This may also point to the fact that the staff concerned have limited knowledge about the nature of their clients. One B.Ed. student had this to say;

"We work from Monday to Friday and the only time I can come to the centre is after $5 \mathrm{pm}$ or over the weekend. These are officially non-working hours and the offices are always closed."

This, therefore, calls for training of the staff in the centres to understand the complexity of ODL students and the need for flexibility when serving them.

\section{$4 \quad$ Conclusion and Implications}

The existence of study centres for Makerere University shows the original commitment of the university to support ODL. However, over time and with many changes in our education systems and structures, the university seems to have lost the vision and this decentralized model of providing student-support is no longer a priority. This study however, noted that there are factors that have worked against the flourishing of these centres, and if addressed the centres can again offer meaningful support to students.

The barriers to effectiveness of study centres of Makerere University are more internal than external. The main barriers are lack of a clear policy to guide the activities of ODL and this has hindered smooth working relationships and communication among different stakeholders i.e. the students, programme administrators and centre staff. The other factor is inadequate funding, which has affected the upgrading of facilities and efficient service delivery. This has manifested itself in terms of ill equipped study centres with inadequate and out- 
dated study materials, no ICT infrastructure to support teaching and learning activities, and no qualified academic staff, ICT administrators and librarians to attend to students' academic concerns. This status has hindered decentralization of students' support services and this has consequently affected the activities of study centres, rendering them non-functional. There is a need for a deliberate effort by the programme administrators to sensitize all stakeholders about the operations of ODL, especially the policy and decision makers in the university about the role of study centres. If the study centres are going to be upgraded and equipped with both human and material resources, then the policy makers need to appreciate their role so as to facilitate them. The staff in the study centres should be sensitized as well about the philosophy of ODL (flexibility) and the nature of students so that they can be available to serve them whenever they attend.

The relevance of study centres in developing countries, which are still running second generation distance education, cannot be understated. From this study, it is evident that those study centres that have been upgraded to campus status have been resourced, so they are in a better position to competently support ODL students. The rest of the study centres should also be revamped and equipped to support the ODL students. The innovations in students' support using ICTs can only reinforce existing support structures but cannot replace them. Institutions offering ODL under such contexts are tasked with exploring strategies of effectively sustaining study centres so as to fulfil their mandate.

\section{Acknowledgement}

The authors gratefully acknowledge support towards completion of this study that was provided by the Cambridge-Africa Programme under the auspices of the Cambridge-Africa Partnership for Research Excellence (CAPREx) and Makerere University.

\section{References}

Aguti, J. N. (2004). A study of In-service Distance Education for Secondary School teachers in Uganda. Developing a Framework for Quality Teachers Education Programme. Unpublished PhD Thesis, University of Pretoria.

Bbuye, J. (2012). Developing a framework for the management of Distance Education learner support for private and public universities in Uganda. $\mathrm{PhD}$ Thesis. Unpublished. 
CCE (1990). A proposal to start the External Degree programme. CCE, Makerere University. Unpublished.

Ipaye, B. (2008). Strategies for sustainable learner support services in developing nations: Learner support services, National University of Nigeria. Retrieved from: http://pcf4.dec.uwi.edu/viewpaper.php?id=57print=1.

Kember, D. \& Dekkers, J. (1988). The role of study centres for academic support in distance education. Distance Education, 8(2), 30-42.

Mills, R. (2002). The role of student centres in open and distance education: A glimpse of the future. In Mills R. and A. Tait (Eds.) Supporting the learner in open and distance learning, pp. 73-87. London: Pitman Publishing.

Moore, M. G. (1993). Theory of Transactional distance. In D. Keegan (Ed.), Theoretical principles of distance education. (pp. 22-38) London / New York: Routledge.

Muyinda, P. B. (2013). Open and Distance learning in Dual Mode Universities: A treasure unexploited. In International Perspectives of Distance Learning in Higher Education. Published by In Tech on line.

Nanyongo, E. P. (2002). Changing entrenched learner support systems. In. Tait \& Mills (eds.), Rethinking learner support in distance education: Change and continuity in an international context. London: Routledge.

Perraton, H. (1993). Distance Education for Teacher Training. London: Routledge.

Robinson, B. (1997). Distance Education for primary teacher training in developing countries. In J. Lynch C. Modgil \&S. Modgil (Eds.) Education and Development: Tradition and Innovations in delivering primary education. London: Cassell Edu Press.

Rumble, G. (1992). Management of Distance Learning System. Paris: UNESCO and IIEP.

Saint, W. (1999). Tertiary Distance Education and Technology in Sub-Saharan Africa. Washington, DC: Working Group on Higher Education, Association for the development of Education in Africa (ADEA) / World Bank.

Simpson, O. (2013). Student's retention in Distance Education: Are we failing the students? The Journal of Open, Distance and E-Learning, 28 (2), 105-119.

Tait, A., R. Mills (2000). Rethinking Learner Support in Distance Education London: Routledge Falmer. pp. 185-197.

Tait, A. (2003). Reflections on students Support in Open and Distance Learning. Journal for international Review of research in Open and Distance Learning. $1,287-299$.

UNESCO (2002). Teacher Education Guidelines: Using Open and Distance Learning. Technology, Curriculum, Cost and Evaluation.

Wrightson, T. and Otto, A. (2005). Makerere University Distance Learning Programmes Evaluation Report. Kampala: Makerere University. 